\title{
Commentary: 'Tis the season to filter your perfusate
}

Yizhan Guo, MD, ${ }^{\mathrm{a}}$ and

Alexander Sasha Krupnick, MD ${ }^{\mathrm{b}}$

Clinical ex vivo lung perfusion (EVLP) for evaluation and reconditioning of marginal lung allografts has been approved by the Food and Drug Administration and is now accepted by most transplantation centers. In addition to clinical studies, investigators continue to improve on this technology using a preclinical porcine model of EVLP. These innovations focus mostly on optimizing the ventilation parameters, ${ }^{1}$ as well as on altering the components of the perfusate ${ }^{2}$ to optimize reconditioning of the grafts. Given the nature of the preexisting injury present in most marginal lung grafts, ameliorating ischemiareperfusion injury is a major focus of such investigations.

In this issue of the Journal, the group from the University of Zurich evaluated the effect of broad and nonspecific cytokine adsorption during the process of EVLP using Cytosorb microporous bead technology (CytoSorbents Europe, Berlin, Germany) on the short-term outcome of porcine lung grafts subject to extremely prolonged ischemic injury. ${ }^{3}$ They demonstrated that the use of broad-spectrum cytokine absorption results in grafts with superior dynamic compliance and improved diffusion capacity during the 6-hour EVLP period compared with grafts perfused via standard EVLP. Lung allograft assessment at 4 hours after reperfusion demonstrated a similar trend for lung function improvement. The authors attributed such advancements to the decrease in proinflammatory cytokines and chemokines, as the adsorbing beads can bind and remove these mediators from the EVLP circuit, thereby "cleaning up" the microenvironment that orchestrates reperfusion injury. This hypothesis was supported by significant decreases in the levels of deleterious cytokines in the bronchoalveolar

\footnotetext{
From the ${ }^{\mathrm{a}}$ Department of Surgery and ${ }^{\mathrm{b}}$ Carter Immunology Center, University of Virginia School of Medicine, Charlottesville, Va.

Disclosures: Authors have nothing to disclose with regard to commercial support.

Received for publication Dec 2, 2019; accepted for publication Dec 2, 2019; available ahead of print Dec 20, 2020.

Address for reprints: Alexander Sasha Krupnick, MD, Department of Surgery, University of Virginia, PO Box 800679, Charlottesville, VA 29908 (E-mail: AK2YF@virginia.edu).

J Thorac Cardiovasc Surg 2021;161:e127-8

$0022-5223 / \$ 36.00$

Copyright (c) 2019 by The American Association for Thoracic Surgery

https://doi.org/10.1016/j.jtcvs.2019.12.012
}

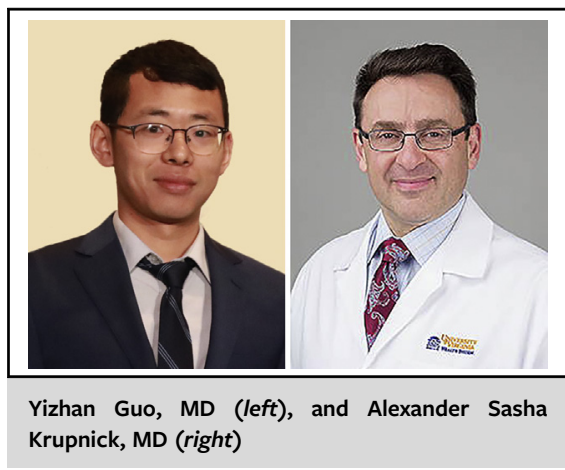

\section{CENTRAL MESSAGE \\ Cytokine adsorption during ex vivo lung perfusion may play a role in improving graft function after implantation.}

lavage fluid, such as interleukin (IL)-8 and IL- $1 \beta$, which can mediate neutrophil recruitment and lung ischemiareperfusion injury. ${ }^{4,5}$

Although this presents a very straightforward approach to eliminating the unwanted proinflammatory factors, we need to recognize that beneficial components of the perfusate might be affected as well. In fact, this is demonstrated by the authors, with decreases in the graft levels of methylprednisolone and meropenem evident even after brief Cytosorb treatment. In addition, the utility of adsorption may be overshadowed by the rapid elaboration of proinflammatory cytokines in the graft after implantation. This is evident in the present study based on the autopsy finding of decreased lavage fluid levels of some, but not all, cytokines. In addition, it is important to remember that in certain situations traditionally considered proinflammatory, cytokines actually may be critical for lung homeostasis and downregulation of the immune responses. ${ }^{6,7}$ Thus, their neutralization may serve a counterintuitive role of breaking rather than establishing tolerance. Nevertheless, the present work by Iskender and colleagues demonstrates an exciting advance in ex vivo organ reconditioning and will serve as a basis for much-needed translational therapy.

\section{References}

1. Niikawa H, Okamoto T, Ayyat KS, Itoda Y, Farver CF, McCurry KR. The protective effect of prone lung position on ischemia-reperfusion injury and lung function in an ex vivo porcine lung model. J Thorac Cardiovasc Surg. 2019;157:425-33.

2. Wagner CE, Pope NH, Charles EJ, Huerter ME, Sharma AK, Salmon MD, et al Ex vivo lung perfusion with adenosine A2A receptor agonist allows prolonged cold preservation of lungs donated after cardiac death. J Thorac Cardiovasc Surg. 2016;151:538-45. 
3. Iskender I, Arni S, Maeyashiki T, Citak N, Sauer M, Caviezel A, et al. Perfusate adsorption during ex vivo lung perfusion improves early post-transplant lung function. J Thorac Cardiovasc Surg. 2021;161:e109-21.

4. Hsiao HM, Fernandez R, Tanaka S, Li W, Spahn JH, Chiu S, et al. Spleen-derived classical monocytes mediate lung ischemia-reperfusion injury through IL-1 $\beta$. J Clin Invest. 2018;128:2833-47.

5. De Perrot M, Sekine Y, Fischer S, Waddell TK, McRae K, Liu M, et al. Interleukin-8 release during early reperfusion predicts graft func- tion in human lung transplantation. Am J Respir Crit Care Med. 2002; 165:211-5.

6. Krupnick AS, Lin X, Li W, Higashikubo R, Zinselmeyer BH, Hartzler H, et al. Central memory CD8 + T lymphocytes mediate lung allograft acceptance. $J$ Clin Invest. 2014;124:1130-43.

7. Konieczny BT, Dai Z, Elwood ET, Saleem S, Linsley PS, Baddoura FK, et al. IFNgamma is critical for long-term allograft survival induced by blocking the CD28 and CD40 ligand T cell costimulation pathways. J Immunol. 1998;160:2059-64. 